
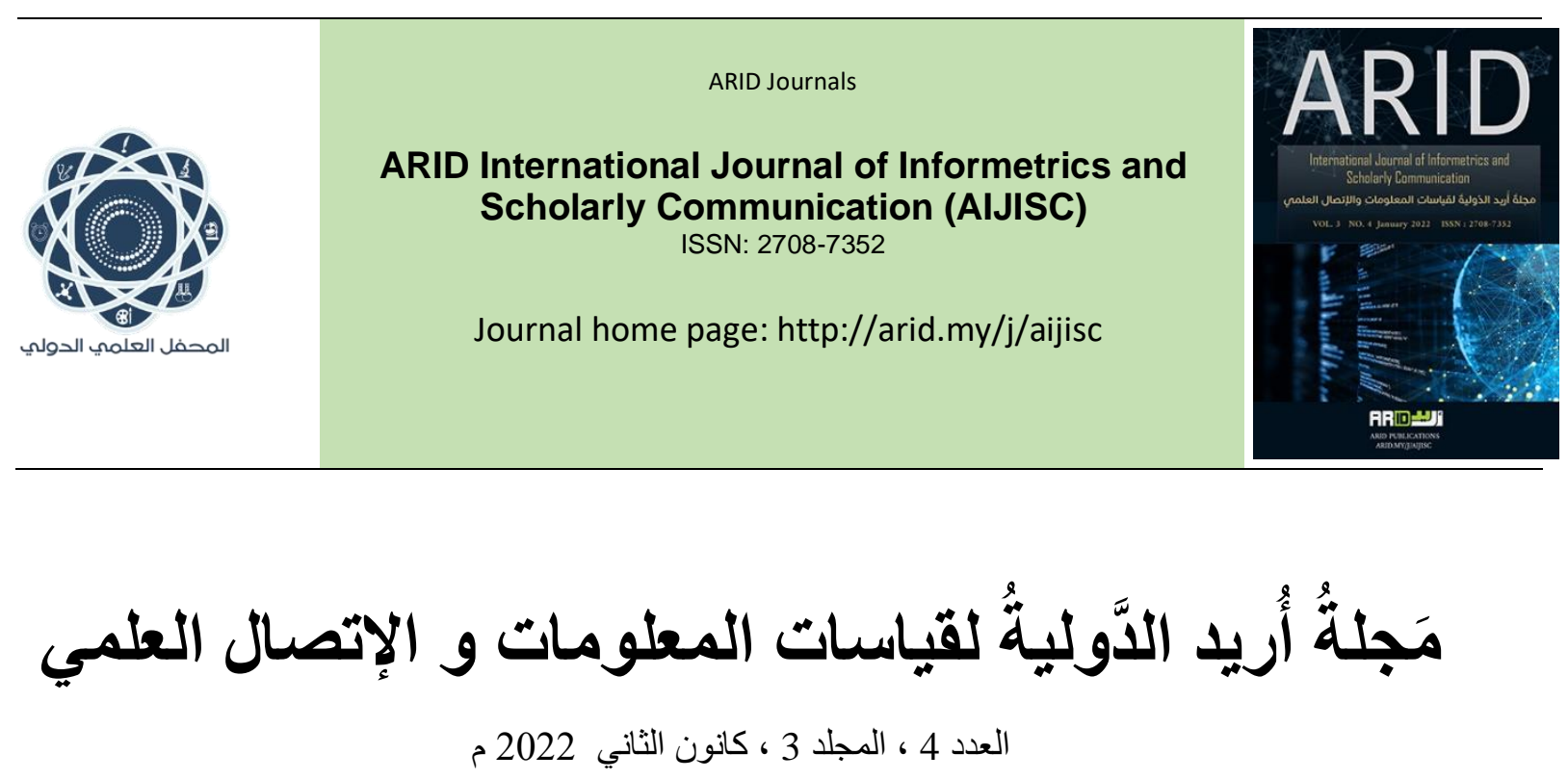

\title{
University Institutional Repositories: an analytical study of the ten best university Repositories
}

\author{
Saher M. Kazem*, Khulood Ali Oraibi \\ Information Sciences Department - Al-Mustansiriyah University - Baghdad - Iraq \\ المستودعات المؤسسية الجامعية: دراسة تحليلية لأفضل عشر مستودعات جامعية \\ ساهر محمود كاظم*، خلود علي عريبي \\ قسم المعلومات و المكتبات ـ كلية الآداب ـ الجامعة المستتصرية ــ العراق
}

Sahir.kazem@yahoo.com

arid.my/0006-4735

https://doi.org/10.36772/arid.aijisc.2022.346 


\begin{tabular}{l}
\hline A R T ICLE INFO \\
\hline Article history: \\
Received 19/04/2021 \\
Received in revised form 21/06/2021 \\
Accepted 20/09/2021 \\
Available online 15/01/2022 \\
\hline
\end{tabular}

\begin{abstract}
The research aimed to study and analyze the best global University institutional repositories, which were selected by the search engines and the Spanish website Metrix. A descriptive approach has been used to carry out the research (survey) and a deliberate sample has been taken (ten university repositories) from a community of 500 repositories mentioned in the directory of free access repositories (open Dora), in terms of content, types of digital content management systems, number of recordings, language used and methods of storage and retrieval. The study found that $70 \%$ of university institutional repositories used the open source Dspace system. Press articles have been ranked first with a percentage of $100 \%$, while theses came in second rank with regard to the substantive content of the repositories. Moreover, it is found that the position of the repository does not depend on the number of existing recordings as much as it depends on the quality, usage and the links of these recordings.
\end{abstract}

Keywords: Digital repositories, University institutional repositories, Analytical study, Free access, Digital libraries. 


\section{الملخص}

يهدف البحث إلى در اسة وتحليل أفضل المستودعات المؤسسية الجامعية العالمية، والتي تم اختيار ها عن طريق محركات البحث وموقع الويب متركس الإسباني. وقد استخدم البحث المنهج الوصفي (المسحي) و تم اخذ عينة عمدية مقدار ها (عشر مستودعات جامعية) من المجتمع والمكون من 500 مستودع تم ذكره ضمن دليل مستودعات الوصول الحر(Open Dora)، وذللك من حيث المحتوى و أنواع نظم إدارة المحتوى الرقمي و عدد التسجيلات واللغة المستخدمة وأساليب الخزن و الاسترجاع. و قد تم التوصل إلى نتائج عدة أهمها: إن 70\% من المستودعات المؤسسية الجامعية استخدمت نظام ديس بيس (Dspace) المفتوح المصدر ، وأن المقالات الصحفية جاءت بالمرتبة الأولى وبنسبة 100\% و الرسائل الجامعية في المرتبة الثانية بالنسبة للمحتوى الموضو عي للمستودعات. كما بيّنت النتائج أن مكانة المستودع لا تعتمد على عدد التسجيلات الموجودة بقدر ما تعتمد على الجودة و الاستخدام و الروابط لهذه التسجيلات.

الكلمات المفتاحية: المستودعات الرقية، المستودعات المؤسسية الجامعية، دراسة تحليلية، الوصول الحر، المكتبات 
إن إن المستودعات الرقمية المؤسسية في المؤسسات الأكاديمية شهدت تطورات عديدة في معظم أنحاء العالم بازدياد ونمو المبادر ات المفتوحة المصدر في التو اصل العلمي وتطوير البرمجيات، وفي هذا الصدد قامت العديد من الجامعات العالمية و العربية والعر اقية بالاستناد إلى مبادرات الأرشفة المفتوحة المصدر عن طريق جمع وأرشفة ونشر المواد العلمية، و إتاحتها من أجل إدارة الوثائق بالطريقة الإكترونية التي تخدم شريحة الباحثين، ومن أبرز تلك البرمجيات المؤسسية الأكاديمية برنامج DSPASE التابع لمؤسسة ماساتشوستس (MIT).

\section{مشكلة البحث:}

تعد المستودعات الرقمية المؤسسية إحدى أنواع المستودعات التي تتيح الوصول الحر إلى مصادر المعلومات الرقمية المتوفرة على شبكة الإنترنت، لذا فإن الدراسة سنتناول أفضل عشرة مستودعات مؤسسية جامعية عالمية تم اختيار ها من تصنيف الويب متركس الإسباني(1) من حيث نوع المحتوى وسنة التأسيس والبرمجيات المستخدمة في إدارة المحتوى الرقمي وعدد التسجيلات وسياسة المستودعات المتبعة في الايداع و الإتاحة، ومنا هنا تتمثل مشكلة البحث من خلال الإجابة على الأسئلة

$$
\begin{aligned}
& \text { 1. ما المستودعات الرقمية المؤسسية؟ } \\
& \text { 2. ما أنو اع برمجيات نظم إدارة المحتوى المستخدمة في إدارة المستودعات؟ } \\
& \text { 3. ما أنو اع المحتوى التي اشتملت عليه تسجيلات المستودعات؟ } \\
& \text { 4. ماسياسة الحفظ و الإتاحة المتبعة في المستودعات؟ } \\
& \text { 5. ما اللغات المستخدمة في المستودعات؟ }
\end{aligned}
$$




\section{أهمية البحث:}

تتبع أهمية البحث من أهمية المستودعات الرقمية الجامعية موضوع البحث وفي توفير مصادر علمية موثوقة سواء للمكتبات أو الباحثين و أهميتها في الحفظ طويل الأمد للنتاج الفكري للجامعة وكذللك أهميتها في در اسة أفضل المحتوى و الذي يمكن الاقتداء بهه عند بناء المستودعات الجامعية.

\section{أهداف البحث:}

$$
\text { بسعى البحث إلى تحقيق الأهداف الآتية: }
$$

1. بيان أفضل أنواع برمجيات نظم إدارة المحتوى المستخدمة في إدارة المستودعات. 2. إجر اء مقارنة بين أنواع المحتوى التي اشتملت عليه تسجيلات المستودعات. 3. عمل مقارنة بين سياسة الحفظ و الإتاحة المتبعة في المستودعات. 4. اللغات المستخدمة في المستودعات. 5. معرفة البلدان التي تنتمي إليها المستودعات الرقمية. منهج البحث:

لغرض حل مشكلة البحث وتحقيق الأهداف استخدم البحث المنهج (الوصفي التحليلي) لملائمته وطبيعية إعداد البحث في الجانب النظري و الجانب التطبيقي للبحث، مع أخذ عينة قصدية لأفضل عشر مستودعات جامعية عالمية من مجتمع مؤلف من 500 مستودع ضمن تصنيف الويب منركس ودليل مستودعات الوصول الحر(Open Dora).

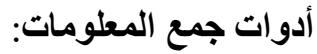
1- محركات البحث عبر الويب.

2- المصادر الرقمية المتعلقة بموضوع الدراسة. 


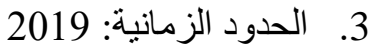

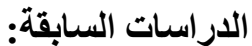

1- در اسة أحمد عبادة العربي (2011) المستودعات الرقمية للمؤسسات الأكاديمية ودور ها في العملية التعليمية والبحثية

$$
\text { و إعداد آلية لإنشاء مستودع رقمي للجامعات العربية (مكتبة الملك فهد، ص149-194) }
$$

The cybermetricsLab هدفت الار اسة إلى فحص أفضل خمسين مستودعا وتحليليها وفقا لترتيب وتوزيع محتوياتها عدديا ونو عياوزمنيا وموضو عيا، وتحديد أساليب البحث و الاسترجاع.

$$
\text { حيث إن الباحث استخدم منهج البحث الوصفي التحليلي واختار عينة عمدية للار اسة. }
$$

منهج الاراسة والعينة

$$
\text { أهم النتائج التي خرجت بها الدراسة: }
$$

1- إن 33\% من المستودعات موضوع الدراسة لم تحدد تاريخ إنشائها وامتد تاريخ إنشاء المستودعات

موضوع الدراسة ما بين 1991 وحنى عام 2009 وكان مستودع Arxiv .org e- هو أقدم

$$
\text { المستودعات التي تم إنشاؤ ها حيث ظهر عام } 1991
$$

2- اعتمدت المستودعات موضوع الدراسة عدة برمجيات في إنشائها، حيث استخدمت75\% من المستودعات موضوع الد راسة برمجيات مفتوحة المصدر وكان برنامج Eprints هو أكثر البرامج التي تم استخدامها، فقد اعتمدت عليه45.83\% .من إجمالي المستودعات موضوع الدراسة، و Dspace 16.67 و أنظمة محلية 25\% و \% \% 4.7Invenio أما أهم توصيات الدر اسة فكانت:

1- ضرورة أن تحرص الجامعات العربية على إنشاء مستودعات رقمية لها على الإنترنت لخدمة العملية التعليمية والبحتية بها وحفظ الأعمال الفكرية لمنسوبيها، ويمكنها الاسترشاد بالآلية التي توصل إليها الباحث.

$$
\text { 2- ينبني الحرص على إتاحة الوصول الحر للمصادر الإلكترونية المدرجة بالمستودع. }
$$

3- ينبغي على المسؤولين عن إدارة المستودع الحرص على تحقيق الذيوع والانتشار له، من خلال التعريف به في اللقاءات العلمية، والمحاضر ات، وإرسال الر ابط الخاص به. للمؤلفين، ومحاولة تسجيله في الأدلة المتخصصة وخاصة دليل: DOAR Directory of Open Access Repository ودليل ROAR: Registry of Open Access Repository 
-2 دراسة (Van Devanter and Pienaar 2008) بعنوان المستودعات الرقمية بجنوب إفريقيا: جسور لتقاسم المعرفة.

هدفت إلى تحليل المستودعات الرقمية التي أنشئت بجنوب إفريقيا في الفترة الممتدة من سنة 2000 إلى 2008 ودور ها في دعم تبادل المعارف والوصول الحر للمعلومات، والمقدر عددها بعشرة مستودعات

$$
\text { مؤسساتية. }
$$

أهم النتائج التي توصلت اليها الدراسة هي:

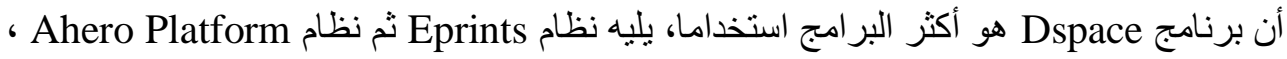
ومن أهم التوصيات التي أوصى بها الباحث هي ضرورة دعم استر اتيجيات ومشاريع بناء المستودعات الرقمية المؤسساتية وحث الباحثين و أعضاء هيئة التدريس بالجامعات على المساهمة في نشر المعرفة. (2008 ‘;Pienaar, Heila ;Deventer, Martie van)

$$
\text { مقارنة الدر اسة مع الدر اسات السابقة: }
$$

1- أثتتت در اسة أحمد عرابي أن (Eprints) هو الأول من حيث النظم المستخدمة في المستودعات موضوع الدر اسة يأتي بعده ثانيا بينما أثبتت دراسة (Dspace) الاستدامة و هو مطابق لما جاء في هذه الدراسة أيضاً و (أي Eprints ثانياً).

2- اعتمدت الدر اسة الحالية على مستودعات الوصول الحر فقط بينما اعتمدت در اسة أحمد عرابي على أنها مختلفة من نظم إدارة المحتوى الرقمي.

3- إن المستودعات موضوع الدر اسة الحالية هي أحدث من حيث التأسيس مقارنة بالمستودعات موضع الدر اسة السابقة.

تعريف المستودعات الرقمية المؤسسية: وقد ذكر سامح زينهم (الجواد، 2015) عدة تعريفات عن المستودعات الرقمية كان أهمها: 
المستودع الرقمي هو: المكان الذي يتم فيه تخزين المحتوى الرقمي و الذي يمكن أن يبحث ويسترجع للاستخدام اللاحق، فالمستودع يدعم تقنيات لاستير اد وتصدير وتعريف واسترجاع المثنكات الرقمية. وقد عرفها (احمد فرج، 2012):

هي عبارة عن قاعدة بيانات متاحة على الثبكة العنكبوتية، تشتمل على الإنتاج الفكري الرقمي الذي يودعه الباحثُون والذي يصدر عن المؤسسة وعادة تتبع الجامعات و المعاهد و المر اكز البحثية بدون قيود و عو ائق، وقد تشمل أنواعاً أخرى من المؤسسات مثل الدو ائر الحكومية أو الوكالات و اتحادات الجمعيات و الكيانات التجارية و التي ترغب في حفظ ونشر منتجاتها مجانا.

ويرى الباحث أن المستودع ليس مؤسسة ولكن هو نظام أو برنامج يتم من خلاله أرشفة النتاج الفكري لمؤسسة معينة وقد يكون متخصصا في فرع من فروع المعرفة ويتم إتاحته على النت لفئة معينة أو للجميع خارج المؤسسة وذللك بعد عمليات الخزن و الإدارة للمحتوى الرقمي و على المدى الطويل ودون مقابل مادي.

\section{فو ائد المستودعات المؤسية الرقمية:}

تتمـتع المسـتودعات المؤسـسية الرقمية بعدة مميز ات وتمنلك إمكانيات وخدمات كثيرة ذات قيمة مضافة لكل من المجتمع العالمي و المؤسسات البحثية والتعليمية و الباحثين و المجتمع العلمي بصفة عامة، ومن أهم تلك الفو ائد:

1. المسـتودع المؤسسي يمكن الجامعة أن تتفاعل مع أنظمة الجامعات الأخرى وزيادة الكفاءة والفاعلية بينها من خلال تبادل

$$
\text { و مشاركة المعلومات. }
$$

2. يعـل على الارتقاء بسمعة وهيبة الجامعة و إبراز مكانتها (اعتماداً على محتوى المستودع). 3. يسمـح للجامعة أو المؤسسة بإدارة حقوق الملكية الفكرية الخاصة بها من خلال رفع الوعي بقضايا حقوق النشر وتسهيل

$$
\text { تسجيل معلومات الحقوق ذات الصلة. }
$$

و يذكر (كرثيو، 2010، صفحة 15) مجـمو عة من الفو ائد لأعضاء هيئة التنريس ومن أهمها الآتي:

$$
\text { 1. ازديـاد معدلات الاطلاع و المشاهدة للأعمال الفكرية للباحثين. }
$$

2. تززيد فرص التو اصل العلمي وتبادل الخبر ات و المعارف بين مصدمي المحتوى لرفع مستواه.

3. تـتيح للباحث معرفة معدل الاطلاع أو التحميل بو اسطة إحصاءات الاستخدام التي تمت على كل ورقة من أور اقه

$$
\text { العلمية المودعة في المستودع. }
$$




\section{محتويات المستودعات الرقمية المؤسسية:}

المستو دعات الرقمية المؤسساتية يمكن أن تضمن المستودعات الرقمية معدل واسع من المحتويات لنوع الأغر اض و المستخدمين، ومجال و هدف كل مستودع وبالتالي طبيعة المحتويات التي سوف تخزن فيه سوف تعتمد على قرار ات سياسية تتم بواسطة كل مستودع أو مدير على حدة، وفيما يتعلق بالمستودعات المؤسساتية بشكل خاص فإن سياسة الإتاحة الحرة للمؤسسة يجب أن تحدد المواد التي سوف يتم قبولها أو تلك التي لا يتم قبولها للإيداع في المستودع المؤسسي، حيث تركز بعض المستودعات على المسودات المحكمة و غير المحكمة للأبحاث بينما الأخرى تمد المحتوى إلى الأنواع الأخرى من البيانات التي تبدو مر غوبة للمتطلبات المحلية. و هنالك عدة أنواع من المحتويات الرقمية التي يمكن إيداعها في المستودعات الرقمية، ومنها: الرسائل/ الأطروحات الجامعية: الخطط و البر امج ومحتوى الدورات و المحاضر ات، العروض التقديمية، أوراق العمل، الكتب الإكترونية، الدوريات والصحف، منشور ات الجامعة، النشر ات الدورية، مخطوطات الكتب، السير الذاتية لأعضاء المؤسسة التي يتبعها المستودع الرقمي.

\section{برمجيات المستودعات الرقمية مفتوحة المصدر:}

تـعد البرمجيات مفتوحة المصدر رائدة في ميدان تطوير البرمجيات، كما أصبحت عملية تطوير البرمجيات مفتوحة المصدر رد فعل قويَّ من جانب مطوّرِي البرامج على القيود القانونية التي تفرضها حقوق الطبع و النشر، و أصبحت البرمجيات مفتوحة المصدر وسيلة فعالة لإنشاء المشروعات الرقمية دون إضافة أعباء مالية على المؤسسات. (حسين، 2017) وتوجد العديد من التعاريف لبرمجيات مفتوحة المصدر Open source software ) : نورد منها تعريف لنسرين. (قباني، 2013،

صفحة 2) و هي برمجيات تم إتاحة الكود الخاص بها من خلال الإنترنت مجانًا وبدون أي رسوم من المالك الأصلي أو المطور مما يشجع المستخدمين على تطوير تلك البرمجيات وفقًا لاحتياجاتهم و إصلاح الأخطاء الناتجة عن الاستخدام. (Reitz, 2016) ومن بين أشهر نظم ادارة المستودعات الرقمية والمفتوحة المصدر هي:

أـ نظام Dspace

يشير مصطلح Dspace إلى المستودع الرقمي للمخرجات الفكرية لمعهد ماساتشوستس، وهو كذلك اسم لبرنامج مفتوح المصدر يستخدم لتشغيل هذا المستودع، و هذا المشروع لا يتضمن فقط معهد ماساتشيستوس للتكنولوجيا ولكن أيضا اتحاد من المؤسسات مثل جامعة كامبريدج وكولومبيا وكورتل والتي قامت بتجهيز برنامج Dspace لأجل دعم تشغيل مستودعاتها الرقمية. ويعتبر 
نظام Dspace منصة (platform)، يستخدم كمستودع رقمي لحفظ وتكثيف و إعادة توزيع المخرجات الفكرية للمنظمة بتتسيقات رقمية، الفلسفة.

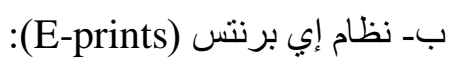
قامت جامعة ساوثامبتون University of Southampton، بتطوير نظام EPrints حيث أطلق في أواخر عام 2000م، وقد كان الهدف من ور اء إيجاد EPrints هو تسهيل الإتاحة المجانية للبحوث العلمية المشتركة، ويعد بمثابة أرشيف للوثائق الالكترونية الأخرى، مثل الصور و السمعيات، ويستخدم EPrints الآن من أكثر من 190 مؤسسة.[ (قباني، 2013، صفحة 4) الجانب التطبيقي للبحث: يتضمن استعر اض عشرة مستودعات عالمية وترتيبها حسب تصنيف الويب متركس، وهذه المستودعات هي: أولا : مستودع المعلومات الأكاديمية لجامعة كيوتو(Kyoto University Research Information Repository) :(OpenDOAR, Kyoto University Research Information Repository, 2020) و هو مستودع مؤسسي يتيح الوصول الحر إلى المصادر الرقمية مجانًا وهو متاح عبر الر ابط: http://repository.kulib.kyoto-u.ac.jp/dspace/ ويتضمن الجدول رقم (1) معلومات عن المستودع الرقمي لجامعة كيوتو: جدول (1) معلومات مستود ع جامعة كيونو

\begin{tabular}{|c|c|}
\hline $\begin{array}{r}\text { مستودع المعلومات الأكاديمية لجامعة كيوتو (Information Repository } \\
\text { (Inoto University Research }\end{array}$ & اسم المستودع \\
\hline اللغة اليابانية و الإنجليزية & واجهة الموقع \\
\hline 2006 & سنة التأسيس \\
\hline احتل المركز الخامس لعام2019 & تصنيف الويب منركس \\
\hline 103 عالميا ضمن نفس التصنيف للويب متركس 2020) & ترتيب الجامعة \\
\hline اليابان & البلد \\
\hline برنامج دس بيس(Dspace) المفتوح المصدر & البرنامج المستخدم \\
\hline
\end{tabular}


Google ) يمكن عن طريقها تكثيف المحتوى باستخدام بيانات جوجل سكولر مبادرة الأرشيف المفتوح)(OAI) Scholar البحوث و النتائج التعليمية و الرسائل و الأطاريح، مقالات صحفية، المراجع أنواع المحتوى الببليو غر افية، تقارير غير منشورة، وأور اق عمل في مو اضيع متعددة التخصصات. يعمل المستودع على الحفظ طويل المدى لمحتوياته ومسئولية المؤلف عن المحتوى سياسة الحفظ

المنشور مع ضمان جميع حقوق الملكية للمؤلف، و عدم السماح بتوزيع أو استنساخ المصادر لأغر اض تجارية.

ثانيا :المكتبة الرقمية لجامعة بيلاروسيا (Belarusian State University Digital Library)

(OpenDOAR, Digital Library Belarusian State Economic University, 2020) و هو مستودع يتيح الوصول الحر إلى المصادر الرقمية لأي شخص مجانًا وهو متاح عبر الرابط: ‘http://edoc.bseu.by:8080/?locale=en

$$
\text { ويتضمن الجدول رقم (2) معلومات عن المستودع الرقمي لجامعة بيلاروسيا: }
$$

\begin{tabular}{|c|c|}
\hline المكتبة الرقية لجامعة بيلاروسيا ( Library) & اسم المستودع \\
\hline اللغة الروسية و الإنجليزية. & واجهة الموقع \\
\hline 2014 & سنة التأسيس \\
\hline احتل المركز السادس لعام 2019 & تصنيف الويب متركس \\
\hline 2020 عالميا ضمن نفس التصنيف للويب مثركس للجامعات. 205 (Universities R. W., & ترتيب الجامعة \\
\hline بيلاروسيا & البلد \\
\hline برنامج دس بيس(Dspace) المفتوح المصدر. & البرنامج المستخدم \\
\hline
\end{tabular}


Google ) يمكن عن طريقها تكثيف المحتوى باستخدام بيانات جوجل سكولر مبادرة الأرشيف المفتوح(OAI) Scholar و إمكانية تصدير و استثر اد التسجيلات اليبليو غر افية لمصادر المعلومات. يحتوي المستودع على رسائل جامعية وأطاريح في مجال العلوم الاجتماعية العامة، أنواع المحتوى الأعمال و الاقتصـاد، القانون و السياسة. يعمل المستودع على الحفظ طويل المدى لمحتوياتها ومسئولية المؤلف عن المحتوى سياسة الحفظ المنشور مع ضمان جميع حقوق الملكية للمؤلف و عدم السماح بتوزيع أو استنساخ

$$
\text { المصادر لأغر اض تجارية. }
$$

ثالثا : مستودع جامعة جادجا مدى ( Universitas Gadjah Mada Repository)

يوفر هذا الموقع الوصول إلى مخرجات البحث في جامعة جادجا مدى، وتحتوي على موجز ات RSS لتنبيه المستخدمين بالمحتوى الجديد (OpenDOAR, Repository Universitas Gadjah Mada, 2020)

$$
\text { و وهو مستودع مؤسسي متاح عبر الرابط: ويتضمن الجدول رقم (3) معلومات عن المستودع الرقمي لجامعة جادجا مدى: }
$$

جدول (3) معلومات مستودع جامعة جادجا مدى

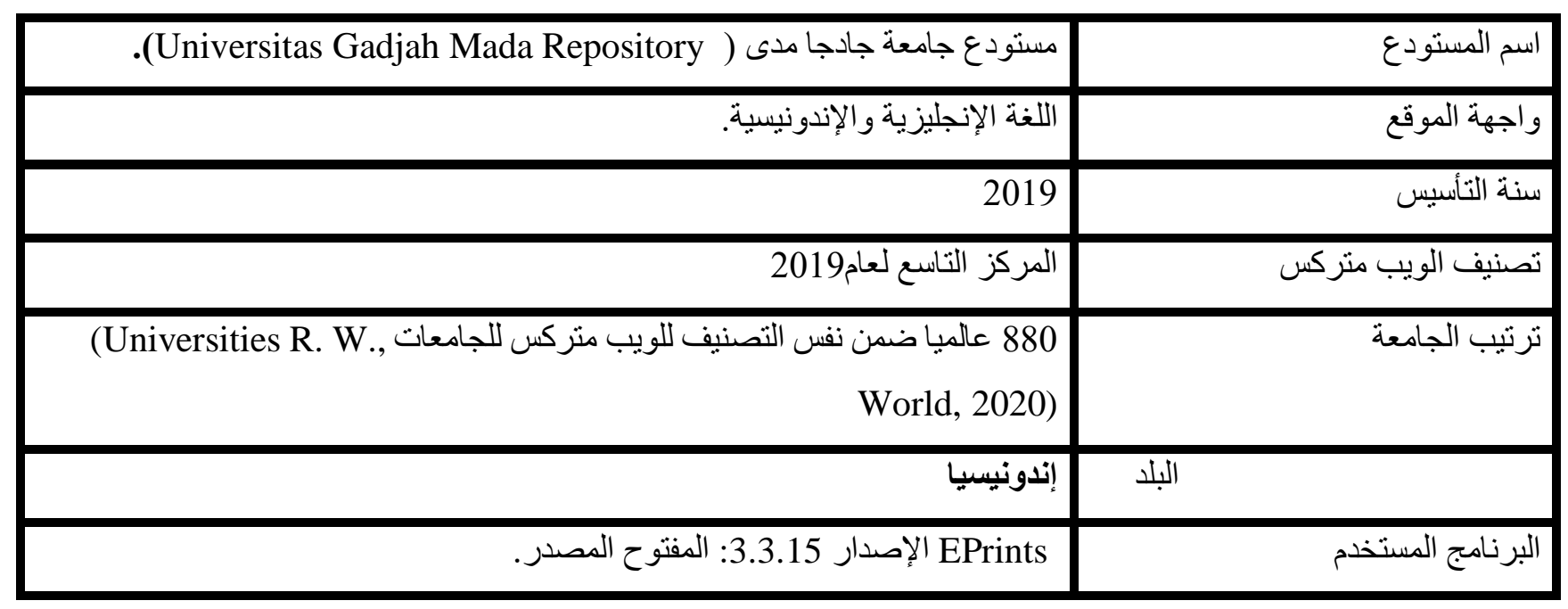


Google ) يمكن عن طريقها تكثيف المحتوى باستخدام بيانات جوجل سكولر مبادرة الأرشيف المفتوح(OAI) Scholar و إمكانية تصدير و استثر اد التسجيلات اليبليو غر افية لمصادر المعلومات. مقالات صحفية، أوراق المؤتمرات، وورش العمل، الكتب و الفصول والأقسام. يعمل المستودع على الحفظ طويل المدى لمحتوياته ومسئولية المؤلف عن المحتوى المنشور مع ضمان جميع حقوق الملكية للمؤلف وعدم السماح بتوزيع أو استنساخ

$$
\text { المصادر لأغر اض تجارية. }
$$$$
\text { غير مذكور. }
$$

\section{رابعا : مستودع جامعة اوترخت(Utrecht University Repository)}

(OpenDOAR, Utrecht University Repository, 2020) و هو مستودع جامعي يوفر الوصول إلى مخرجات منشورات جامعة أوترخت وغير ها من الموارد، مثل الخرائط. وهو مستودع يتيح الوصول الحر إلى بعض المصادر الرقمية لأي شخص مجانًا وقسم آخر يكن الوصول مقيد لفئة معينة وهو متاح عبر الرابط:

http://dspace.library.uu.nl

$$
\text { ويتضمن الجدول رقم (4) معلومات عن المستودع الرقمي لجامعة اوترخت: }
$$

\begin{tabular}{|c|c|}
\hline مستودع جامعة اوترخت(Utrecht University Repository) & 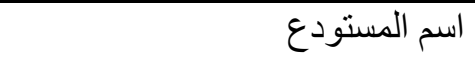 \\
\hline اللغة الهولندية و الإنجليزية & واجهة الموقع \\
\hline 2006 & سنة التأسيس \\
\hline المركز العاشر لعام 2019 & تصنيف الويب متركس \\
\hline 60 عالميا ضمن نفس التصنيف للويب متركس (Universities R. W., World, & ترتيب الجامعة \\
\hline 2020) & \\
\hline هولندا (Netherlands) & 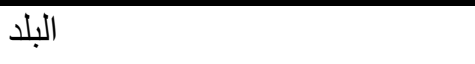 \\
\hline برنامج دس بيس (Dspace) المفتوح المصدر & البرنامج المستخدم \\
\hline 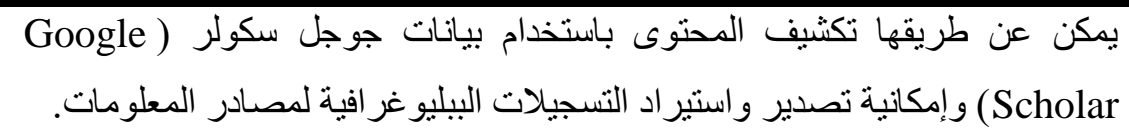 & مبادرة الأرشيف المفتوح (OAI) \\
\hline
\end{tabular}

جدول (4) معلومات مستودع جامعة اوترخت 


\begin{tabular}{|c|c|}
\hline مقالات صحفية أور اق المؤتمر ات، وورش العمل رسائل جامعية (ماجستير ودكتور اه)، & أنواع المحتوى \\
\hline 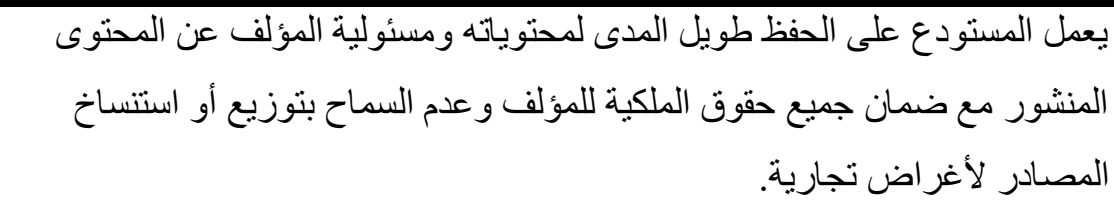 & سياسة الحفظ \\
\hline 167621 (البيانات الوصفية: 167621 النص الكامل: 1652) & عدد التسجيلات \\
\hline تابعة لإدارة مكتبة الجامعة & إدارة المستودع \\
\hline
\end{tabular}

خامسا : المستودع المؤسسي الوطني لجامعة تثياو تونغ National Chiao Tung University Institutional

Repository)

(OpenDOAR, National Chiao Tung University Institutional Repository, 2020) و هو مستودع مؤسسي يوفر إمكانية الوصول إلى نتائج البحوث الخاصة بالمؤسسة، وبعض العناصر غير متوفرة كنص كامل،. يمكن للمستخدمين إعداد قنو ات RSS لتنبيهـهم إلى محتوى جديد. و وهو متاح عبر الرابط: http://ir.lib.nctu.edu.tw ويتضمن الجدول رقم (5) معلومات عن المستودع الرقمي لجامعة تثبياو تونغ: جدول (5) معلو مات مستودع جامعة تشياو نونغ

\begin{tabular}{|c|c|}
\hline $\begin{array}{r}\text { (National Chiao Tung المستودع المؤسسي الوطني لجامعة تتشياو تونغ } \\
\text { University Institutional Repository) }\end{array}$ & 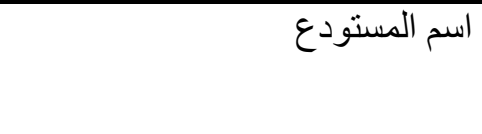 \\
\hline اللغة الإنجليزية و الصينية و الصينية (المبسطة) & واجهة الموقع \\
\hline 2008 & سنة التأسيس \\
\hline المركز الثامن عشر لعام 2019 & تصنيف الويب متركس \\
\hline $\begin{array}{r}369 \text { عالميا ضمن نفس التصنيف للويب متركس للجامعات, (Universities R. W } \\
\text { World, 2020) }\end{array}$ & ترتيب الجامعة \\
\hline Taiwan (Province of China)تايو ان (مقاطعة الصين) & البلد البل \\
\hline
\end{tabular}




\begin{tabular}{|c|c|}
\hline برنامج دس بيس(Dspace) المفتوح المصدر & البرنامج المستخدم \\
\hline 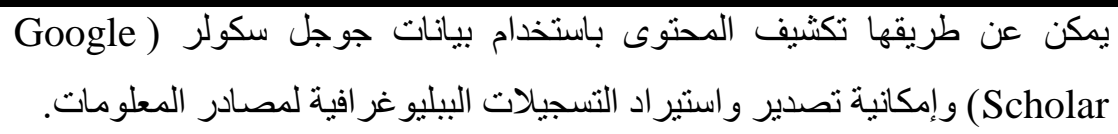 & مبادرة الأرشيف المفتوح(OAI) \\
\hline مقالات صحفية رسائل جامعية (ماجستير ودكتور اه)، أنواع العناصر الخاصة الأخرى. & 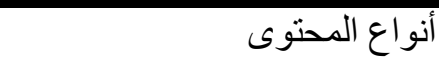 \\
\hline المعنل المستودع على الحفظ طويل المدى لمحتوياته ومسئولية المؤلف عن المحتوى المدان جميع حقوق الملكية للمؤلف وعدم السماح بتوزيع أو استنساخ & سياسة الحفظ \\
\hline 85681 & عدد التسجيلات \\
\hline
\end{tabular}

سادسا : المستودع الرقمي لجامعة سومطرة او تارا(University of Sumatera Utara Repository )

(OpenDOAR, Repositori Institusi Universitas Sumatera Utara, 2020)

يوفر هذا الموقع الوصول إلى مخرجات البحث للمؤسسة. يمكن للمستخدمين إعداد خلاصات RSS لتنبيهها بالمحتوى الجديد. بعض العناصر متاحة فقط للمستخدمين المحلبين. و وهو متاح عبر الرابط:بh://repository.usu.ac.id ويتضمن الجدول رقم (6) معلومات عن المستودع الرقمي لجامعة سومطرة او تار ا: جدول (6) معلومات مستودع جامعة سومطرة او تار ا

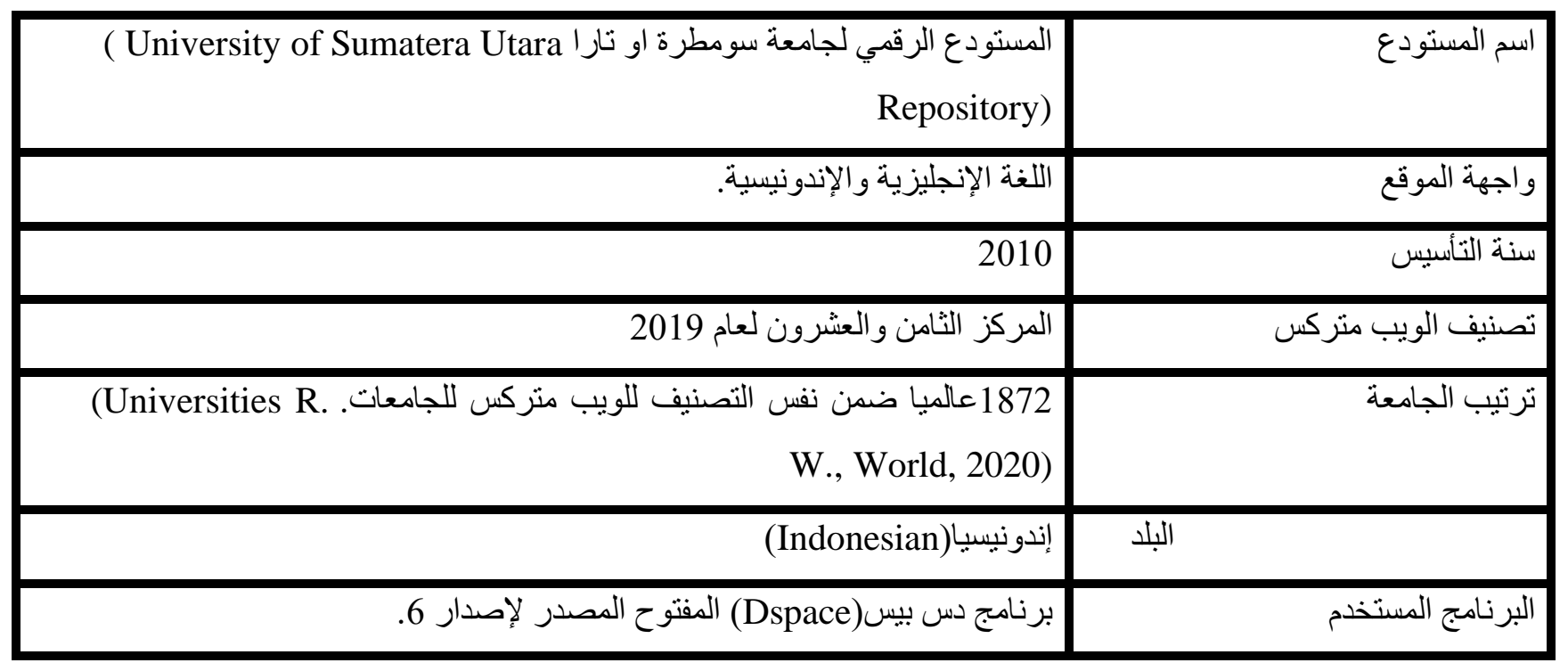




\begin{tabular}{|c|c|}
\hline 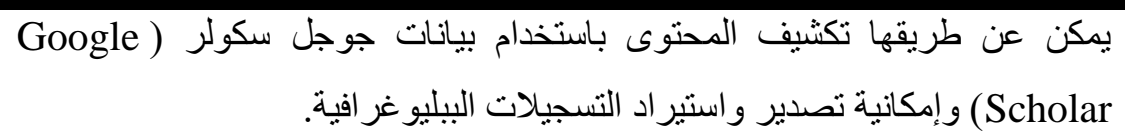 & مبادرة الأرشيف المفتوح)(OAI) \\
\hline منشالات صحفية رسائل جامعية (ماجستير ودكتور اه)، تقارير وأوراق عمل غير & أنواع المحتوى \\
\hline 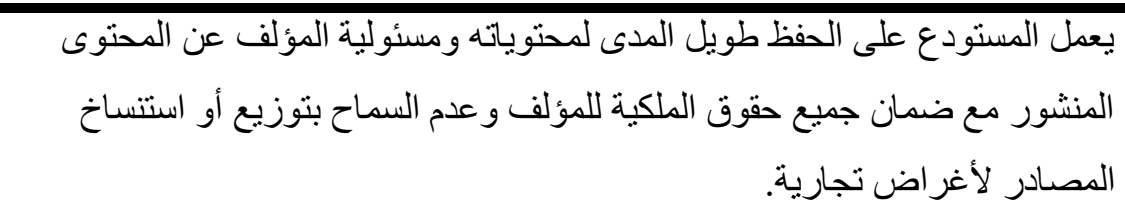 & سياسة الحفظ \\
\hline 64987 & عدد التسجيلات \\
\hline
\end{tabular}

سابعا : المستودع الرقمي لجامعة نانيانغ التكنولوجية Digital Repository Nanyang Technological )

University)

(OpenDOAR, DR-NTU Open Access, 2020)

و هو مستودع رقمي مؤسسي نابع لجامعة نانيانغ التكنولوجية يوفر هذا المستودع إمكانية الوصول إلى نتائج البحوث الخاصة

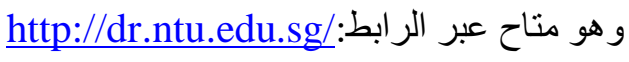

$$
\begin{aligned}
& \text { ويتضمن الجدول رقم (7) معلومات عن المستودع الرقمي لجامعة نانيانغ التكنولوجية: } \\
& \text { جدول (7) معلومات مستودع جامعة نانيانغ التكنولوجية }
\end{aligned}
$$

\begin{tabular}{|c|c|}
\hline $\begin{array}{r}\text { (Digital Repository Nanyang المستودع الرقمي لجامعة نانيانغ التكنولوجية } \\
\text { Technological University) }\end{array}$ & 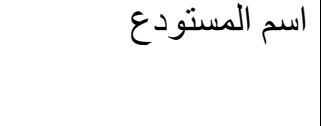 \\
\hline اللغة الإنجليزية & واجهة الموقع \\
\hline 2006 & سنة التأسيس التس \\
\hline التاسع و العشرون لعام 2019 & تصنيف الويب متركس \\
\hline $\begin{array}{r}\text { (Universities R. W., . } 91 \text { عالميا ضمن نفس التصنيف للويب متركس للجامعات } \\
\text { World, 2020) }\end{array}$ & ترتيب الجامعة \\
\hline سنغافورة(Singapore) & \\
\hline برنامج دس بيس(Dspace) المفتوح المصدر الإصدار2. 6 & البرنامج المستخدم \\
\hline
\end{tabular}




\begin{tabular}{|c|c|}
\hline 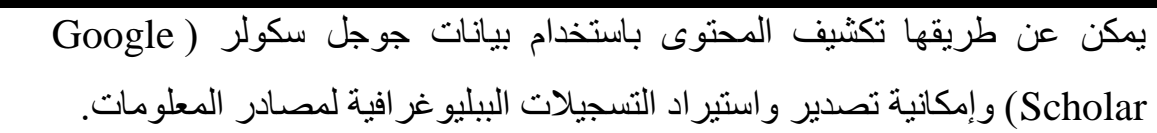 & مبادرة الأرشيف المفتوح(OAI) \\
\hline مقالات صحفية: أور اق المؤتمر ات، ورش العمل مقالات صحفية: أوراق المؤتمر ات، ورش & أنو اع المحتوى \\
\hline 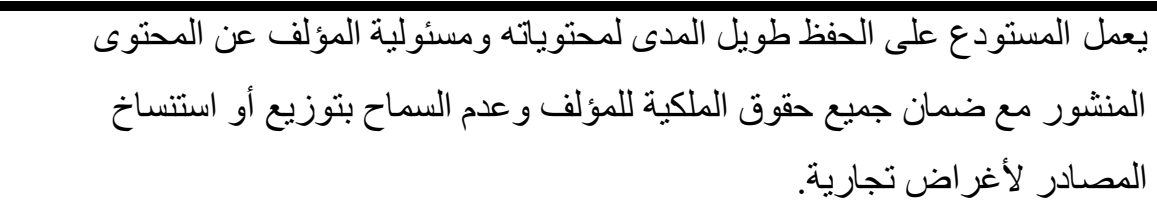 & سياسة الحفظ \\
\hline 27382 & عدد التسجيلات \\
\hline
\end{tabular}

ثامنا : المستودع المؤسسي بجامعة دييونيجورو(Diponegoro University Institutional Repository)

(OpenDOAR, UNDIP -IR, 2020)

و هو مجموعة رقمية من مخرجات جامعة ديبونيجورو الفكرية يوفر هذا المستودع إمكانية الوصول إلى المو اد العلمية التي تعرض مخرجات البحث الخاصة بالمؤسسة، ويوفر المستودع خدمةRSS للمستخدمين لتنبيههم إلى المحتوى الجديد. وهو متاح undip.ac.id.http://eprints عبر الر ابط:

$$
\text { ويتضمن الجدول رقم (8) معلومات عن المستودع الرقمي لجامعة ديبونيجورو }
$$

المستودع المؤسسي بجامعة ديبونيجورو (Diponegoro University Institutional اسم المستودع (Repository

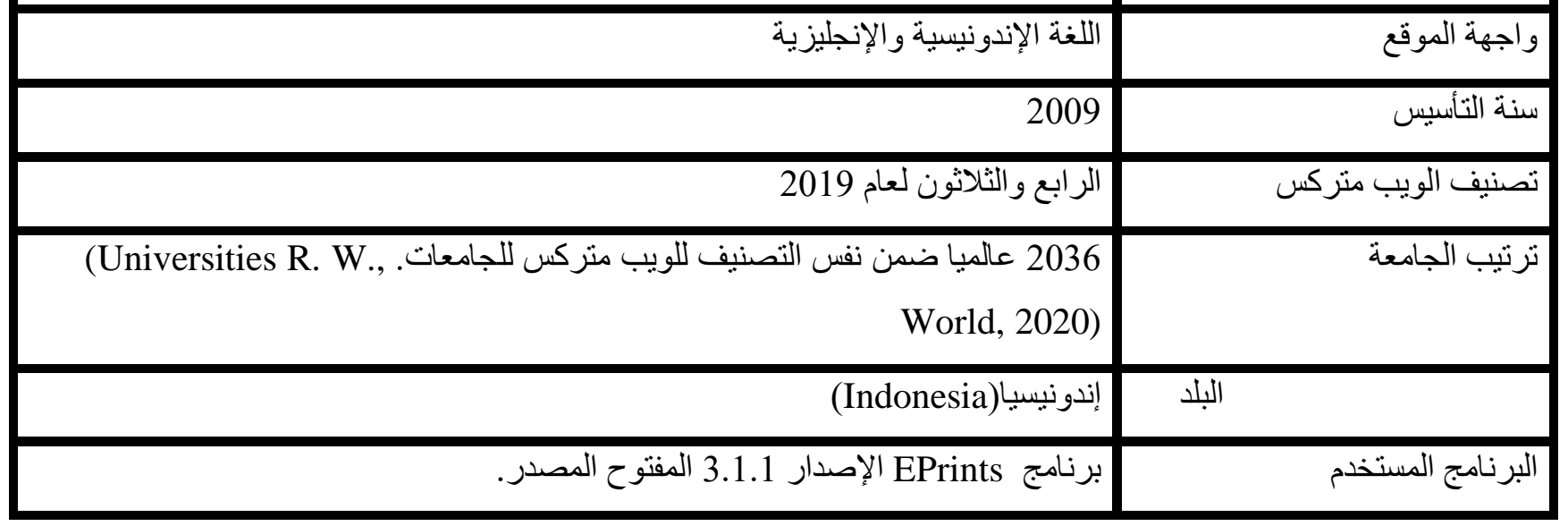




\begin{tabular}{|c|c|}
\hline 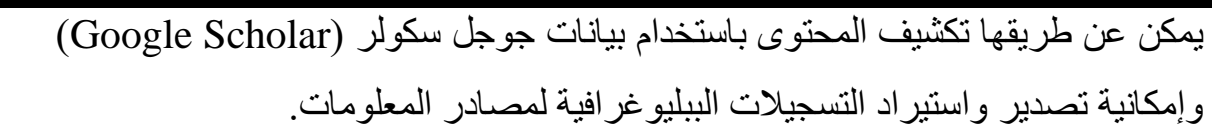 & مبادرة $\quad$ المفتوح(OAI $\quad$ الأرشيف \\
\hline 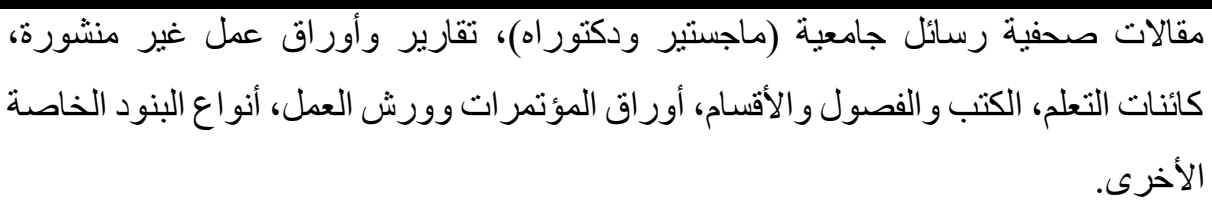 & أنواع المحتوى \\
\hline الا يتم حذف العناصر المسحوبة في حد ذاتها، ولكن تتم إز التها من العرض العام أجل غير مسمى. & طريقة السحب \\
\hline 55307 & عدد التسجيلات \\
\hline
\end{tabular}

تاسعا : المستودع ديب بلو في جامعة ميشيغان(Deep Blue at the University of Michigan)

(OpenDOAR, Deep Blue at the University of Michigan, 2020)

و هو موقع يشتمل على مستودعين: الأول، الذي يعمل حاليًا على DS pace ، وهو مستودع وثائق المؤسسة ويوفر الوصول إلى

مخرجات المنشور ات للمؤسسة، و الثاني الذي يعمل على Fedora ، وهو مستودع بيانات لبيانات البحث الرقمي التي تم تطوير ها أو استخدامها في عملية الأنشطة البحثية في المؤسسة. وهو متاح عبر الرابط: http:/deepblue.lib.umich.edu

$$
\text { ويتضمن الجدول رقم (3) معلومات عن المستودع الرقمي لجامعة جامعة ميشيغان: جدول (9) معلومات مستودع جامعة ميشيغان }
$$

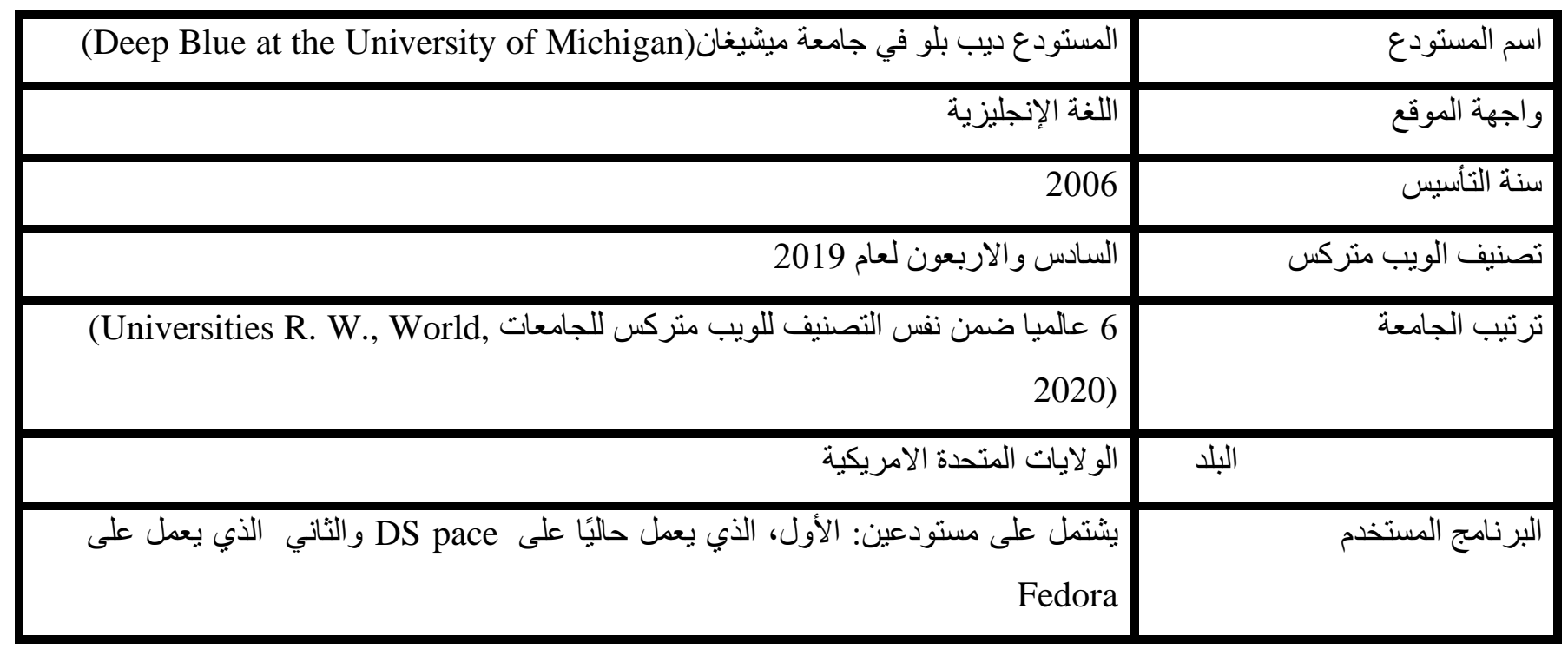




\begin{tabular}{|c|c|}
\hline 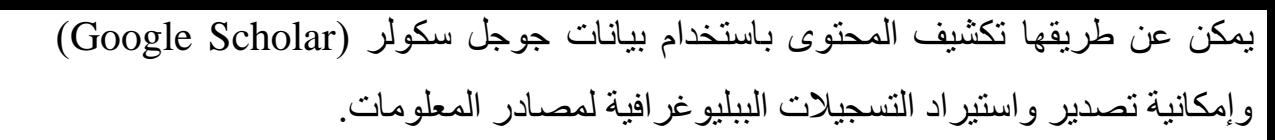 & المفتوح) \\
\hline 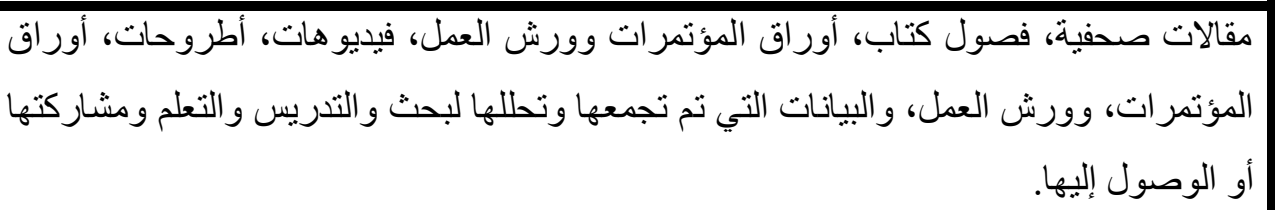 & أنواع المحتوى \\
\hline 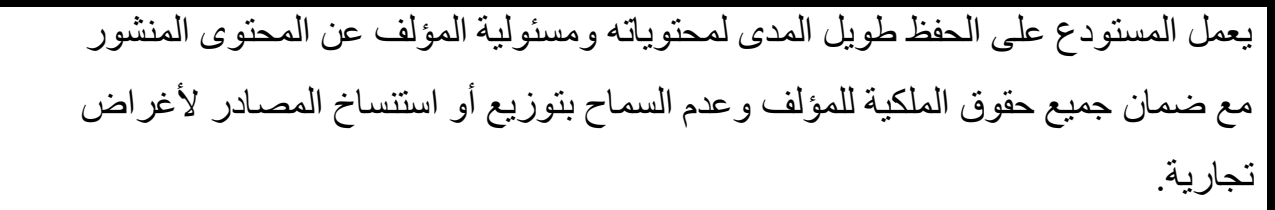 & سياسة الحفظ \\
\hline 120116 & سجيلات \\
\hline
\end{tabular}

عاشرا : المستودع الرقمي لجامعة نيو مكسيكو(University of New México Digital Repository)

(OpenDOAR, University of New Mexico Digital Repository, 2020)

هذا الموقع هو مستودع جامعي يوفر الوصول إلى مخرجات النشر للمؤسسة، ويعد هذا المستودع غنيًا بشكل خاص بمسح التصوير المجهري الإلكتروني والأطياف، والتي تضم حاليًا ثلاثة أرباع العناصر المتاحة، ويمكن للمستخدمين إعداد تنبيهات البريد الإكتروني لإبلاغهم بالمحتوى ذب الصلة المضافة حديثًا، و المستودع الرقمي للبعثة هو مبادرة تعاونية ترعاها مكتبات الجامعة ومكتبة العلوم الصحية ومركز المعلوماتية ومكتبة القانون، وتستضيف هذه الخدمة عملً علميًا من قبل أعضاء هيئة التدريس و الباحثين في بعثة الأمم المتحدة. وهو متاح عبر الرابط: وئ و

$$
\text { ويتضمن الجدول رقم (10) معلومات عن المستودع الرقمي لجامعة نيو مكسيكو: جدول (10) معلومات مستودع جامعة نيو مكسيكو }
$$

المستودع الرقمي لجامعة نيو مكسيكو University of New México Digital

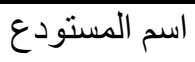
Repository). اللغة الإنجليزية واجهة الموقع 


\begin{tabular}{|c|c|}
\hline التاسع و الاربعون لعام 2019 & تصنيف الويب منركس \\
\hline 2020) 152 عالمياضمن نفس التصنيف للويب متركس للجامعات, Universities R. W., World, & 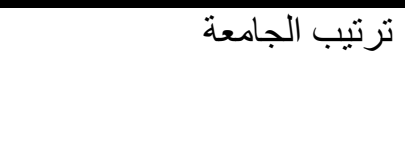 \\
\hline الو لايات المتحدة الامريكية(United States of America) & 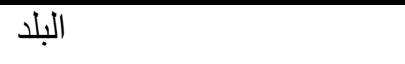 \\
\hline برنامج (المشاع الرقمي). & البرنامج المستخدم \\
\hline 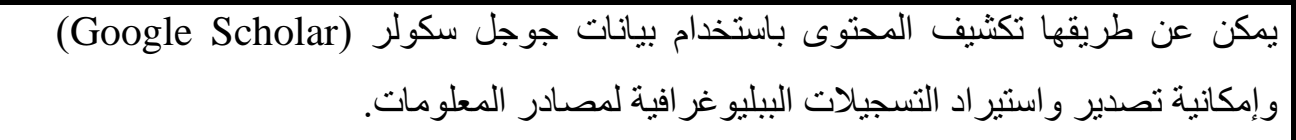 & مبادرة \\
\hline منشالات صحفية، الرسائل الجامعية، أ وراق المؤتمرات، وورش العمل، تقاريز وأوراق عمل غير & أنواع المحتوى \\
\hline في حالة انتهاك حقوق الطبع و النشر أو الانتحال و المتطلبات القانونية و الانتهاكات المثبتة. & أسباب الانسحاب \\
\hline 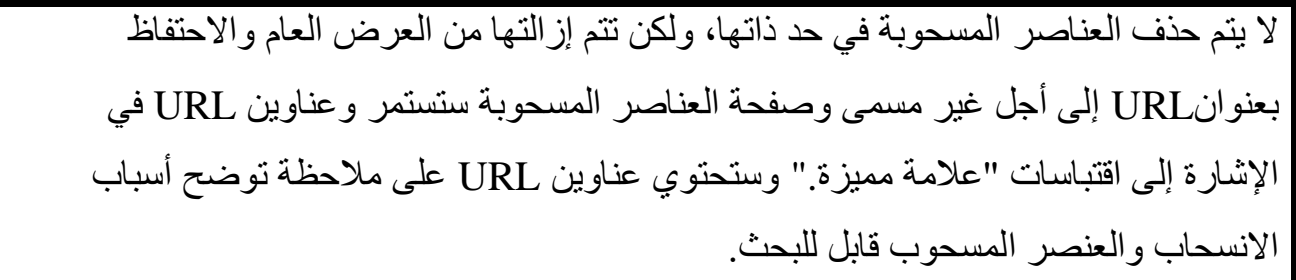 & 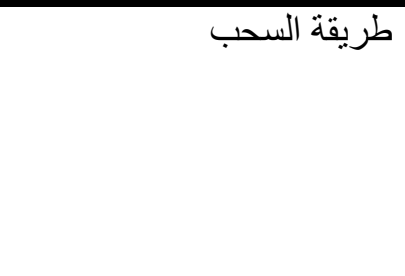 \\
\hline 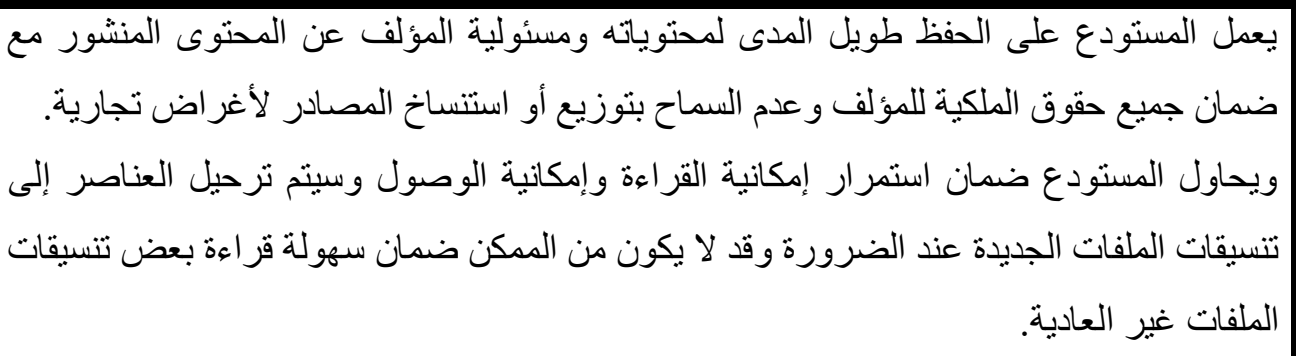 & 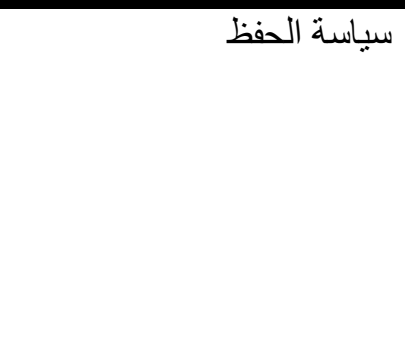 \\
\hline 27217 & عدد التسجيلات \\
\hline
\end{tabular}

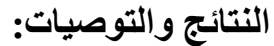

أولا : النتائج:

1. يتبين أن مستودع جامعة كيوتو جاء بالمرتبة الأولى يليه مستودع جامعة بيلاروسيا ثنانيا، ومستودع جامعة جادجا مدى

ثالثا، ومستودع جامعة اوترخت رابعا، ومستودع جامعة تشياو تونغ خامسا، ومستودع جامعة سومطرة او تار ا سادسا،

ومستودع جامعة نانيانغ التكنولوجية سابعا، ومستودع جامعة دييونيجورو ثامنا، ومستودع جامعة ميشيغان تاسعا،

$$
\text { وستودع نيو مكسيكو عاثر ا. }
$$


2. وبالنسبة لأعداد المستودعات حسب الدول فقد جاءت أندونوسيا بثلاث مستودعات وبنسبة 30\%، تلتها أميركا باثثين وبنسبة 20\%، ثم بقية الدول لكل منها مستودع و احد، وبنسبة 10\% و هذا يدل على تتوع الدول التي حصلت على مر اكز متقدمة ولا يقتصر على الدول المتقدمة عالميا كأمريكا وأورباو اليابان. 3. تنين أن نظام إدارت المحتوى الرقمي دسبيس (Dcpase) جاء أو لا وبنسبة 70\% ويليه Eprint وبنسبة 20\% ويليه المشاع الرقمي وبنسبة 10\%و هذا يدل على مكانة ومميزات نظام دسبيس (Dcpase) و انتشار استخدامه عالمياو وبدون منازع من بقية الأنظمة المفتوحة المصدر ، وكذلك احتل مر اكز متقدمة بين بقية النظم التجارية و المحلية عالميا، وحسب

$$
\text { ترنيب الويب منركس الإسباني. }
$$

4. بالنسبة لسنوات التأسيس فقد تباينت ولكن كانت سنة 2006 هي الأكثر سنة تكرارا فقد تأسس أربع مستودعات تلتها باقي السنوات بمستودع واحد، ورغم ذلك فإن سنة التأسيس لا تدل على جودة المستودع فقد حصل المستودع الذي

$$
\text { تأسس عام } 2019 \text { على المركز الثاني في الترتيب. }
$$

5. بالنسبة لأنو اع المواضيع فإن المقالات الصحفية مثلت النسبة الأكبر وبواقع 100\% تلتها الرسائل الجامعية وباقي

$$
\text { المواضيع من أوراق مؤتمرات وأوراق عمل وكائنات تعلم. }
$$

6. تبين أن اللغة الإنكليزية هي الأولى من حيث الاستخدام في جميع المستودعات.

1- إنشاء مستودع رقمي لكل جامعة وذللك للحفاظ على نتاجها الفكري و إتاحته للمستفيدين.

2- استخدام نظام دس بيس (dspace) و هو أفضل نظم إدارة المحتوى الرقمي مفتوحة المصدر.

3- إقامة الورش و المحاضر ات للتعريف بأهمية المستودعات الرقمية للجامعات و المكتبات و الباحثين.

4- إقامة الورش و المحاضر ات تبين كيفية استخدام المستودعات الرقمية من لدن المستفيدين.

5- تشجيع الباحثين على نشر أبحاثهم في المستودعات الرقمية وذلك عن طريق دعمهم معنويا بإعطائهم نقاط تقيم لكل بحث

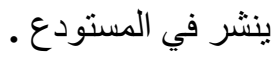


إيمان رمضان محمد حسين. (2017). برمجيات المستو دعات الرقمية مفتوحة المصدر بالمكتبات الجامعية المصرية ودور ها في دعم التتمية الاقتصادية: الو اقع و المأمول ـ ساييرين.

ابر اهيم كرثيو. (2010). المكتبات الاكاديمية و المستودعات الرقية المؤسسية مهام وادوار جديدة. RIST، صفحة 14. احمد عبادة العربي. (2011). المستودعات الرقمبة للمؤسسات الأكاديمية ودورها في العطلية التعليمبية والبحثية واعداد آلية لإنثاء مستودع رقهي للجامعات العربية، مكتبة الملك فهد. مكتبة الملك فهر، الصفحات 149-194. ايمان فوزي عمر. (12, 2011). نشاة وتطور المستودعات الرقمية المفتوحة. سابيربن.

حنان احمدفرج. (2012). المستودعات المؤسسية الرقمية ودور ها في دعم المحتوى العربي و إثر ائه على الإنترنت. . مجلة مكتبة الملك فرا الوطنية، 18 ، صفحة 104. سامح زينهم عبد الجو اد. (2015). المستودعات الرقمبة /ستر/تيجيات البناء والادارة والتسويق والحفظ. بنها: دار الكتاب الحديث. مختار بن هندة. (2005). الخصائص الأرشيفية بين الثبكات المحلبة ومبادرة الأرشيفات المفتوحة . نسرين عبد اللطيف قباني. (2013). نظم بناء المستودعات الرقمية: نظام Dspace نموذجاً. ساييرين، صفحة 4.

DuraSpace. (2019). Fedora . Retrieved from https://duraspace.org/fedora/

Islandora. (2019). Retrieved from Islandora: https://islandora.ca/

OpenDOAR. (2020). Retrieved 3 17, 2020, from Digital Library Belarusian State Economic University: https://v2.sherpa.ac.uk/id/repository/2948?template=opendoar

OpenDOAR. (2020). Deep Blue at the University of Michigan. Retrieved 3 20, 2020, from OpenDOAR: https://v2.sherpa.ac.uk/id/repository/419?template=opendoar

OpenDOAR. (2020). DR-NTU Open Access. Retrieved 3 19, 2020, from OpenDOAR: https://v2.sherpa.ac.uk/id/repository/1392?template=opendoar

OpenDOAR. (2020). Kyoto University Research Information Repository. Retrieved 3 12, 2020, from OpenDOAR: https://v2.sherpa.ac.uk/id/repository/916?template=opendoar

OpenDOAR. (2020). National Chiao Tung University Institutional Repository. Retrieved 3 17, 2020, from OpenDOAR: https://v2.sherpa.ac.uk/id/repository/1321?template=opendoar 
OpenDOAR. (2020). Repositori Institusi Universitas Sumatera Utara. Retrieved 3 18, 2020, from OpenDOAR: https://v2.sherpa.ac.uk/id/repository/1717?template=opendoar

OpenDOAR. (2020). Repository Universitas Gadjah Mada. Retrieved 3 17, 2020, from OpenDOAR: https://v2.sherpa.ac.uk/id/repository/5782?template=opendoar

OpenDOAR. (2020). UNDIP -IR. Retrieved 2 19, 2020, from OpenDOAR: https://v2.sherpa.ac.uk/id/repository/1635?template=opendoar

OpenDOAR. (2020). University of New Mexico Digital Repository. Retrieved 3 20, 2020, from OpenDOAR: https://v2.sherpa.ac.uk/id/repository/336?template=opendoar

OpenDOAR. (2020). Utrecht University Repository. Retrieved 3 17, 2020, from OpenDOAR: https://v2.sherpa.ac.uk/id/repository/101?template=opendoar

Reitz, J. M. (2016). Dictionary for Library and Information Science. westport: ABC-CLIO Corporate.

Universities, R. W. (2020). WOrld. Retrieved 3 18, 2020, from Ranking Web of Universities: http://www.webometrics.info/en/world?page=19

Universities, R. W. (2020). world. Retrieved 3 17, 2020, from RANKING Web of Universities: http://www.webometrics.info/en/world?page=7

Universities, R. W. (2020). World. Retrieved 3 15, 2020, from Ranking Web of Universities: http://www.webometrics.info/en/world?page=1

Universities, R. W. (2020). World. Retrieved 3 17, 2020, from Ranking Web of Universities: http://www.webometrics.info/en/world

Universities, R. W. (2020). World. Retrieved 3 17, 2020, from Ranking Web of Universities: http://www.webometrics.info/en/world?page=8

Universities, R. W. (2020). World. Retrieved 3 19, 2020, from Ranking Web of Universities: http://www.webometrics.info/en/world

Universities, R. W. (2020). World. Retrieved 3 19, 2020, from Ranking Web of Universities: http://www.webometrics.info/en/Americas/USA

Universities, R. W. (2020). World. Retrieved 3 20, 2020, from Ranking Web of Universities: http://www.webometrics.info/en/search/Rankings/New\%20Mexico 